\title{
O USO DA HISTÓRIA NO ENSINO DE MATEMÁTICA (uma reflexão)
}

\author{
THE USE OF HISTORY IN TEACHING MATHEMATICS (a reflection)
}

\author{
Antonio Rennan Sales ${ }^{1}$
}

RESUMO: O presente artigo tem como objetivo promover uma abordagem da disciplina de Matemática aliada à História. A relação entre essas duas áreas do conhecimento, aparentemente colocadas em estanques distantes, na verdade, possibilitam ao aluno uma visão mais geral dos assuntos matemáticos que estão sendo trabalhados em sala. O problema é que a Matemática é vista como uma ciência separada das outras se torna algo que precisa ser revisto. Para D'Ambrósio, um dos maiores erros da Educação Matemática é desvinculá-la das outras atividades humanas. O desafio para o professor é que falta justamente habilidades/mecanismos para que, possa torná-los palatáveis conceitos e aplicações para um aluno que não vê sentido algum no que é visto numa sala. Para discutirmos sobre o tema, foi feita uma pesquisa bibliográfica, que trazem contribuições para uma reflexão ao trabalho do professor de Matemática para que, o ensino não se torne algo monótono e repetitivo.

Palavras-chave: Ensino. História. Matemática.

ABSTRACT: This article aims to promote an approach to the subject of Mathematics allied to History. The relationship between these two areas of knowledge, apparently placed in distant stanzas, in fact, enable the student to have a more general view of the mathematical issues being worked on in the classroom. The problem is that Mathematics is seen as a science separate from others becomes something that needs to be reviewed. For D'Ambrósio, one of the biggest mistakes of

\footnotetext{
${ }^{1}$ Licenciado em Matemática pelo Instituto Federal de Educação, Ciência e Tecnologia Campus Juazeiro do Norte - CE. Especialização em Geometria Euclidiana pela Universidade Regional do Cariri - URCA. Atualmente é professor do Instituto Federal do Sertão Pernambucano Campus Ouricuri - PE
} 
Mathematics Education is to disconnect it from other human activities. The challenge for the teacher is that they lack precisely the skills/mechanisms to make concepts and applications palatable to a student who does not see any sense in what is seen in a classroom. In order to discuss this topic, a bibliographic research was carried out, which brings contributions to a reflection on the work of the Mathematics teacher so that teaching does not become something monotonous and repetitive.

Keywords: Teaching. History. Mathematics.

\section{INTRODUÇÃO}

O ensino de Matemática, na educação básica, exibe números alarmantes em relação ao que os estudantes estão, de fato, aprendendo sobre o que é visto em sala de aula. Em relação ao Pisa (Programa Internacional de Avaliação dos Estudantes) temos que "dos resultados do Pisa conclui-se, por exemplo, que a maioria dos alunos brasileiros de 15 anos não detém conhecimentos básicos para, segundo os parâmetros da pesquisa, exercer plenamente sua cidadania”. (NOBLAT, 2017).

Uma enorme quantidade de alunos tem baixo nível de proficiência em relação a essa disciplina, tornando com que o tema da dificuldade no aprendizado de Matemática seja algo recorrente em vários estudos, simpósios, palestras e afins, todos com o intuito de tentar responder esse problema.

Isso se deve, principalmente porque a Matemática é apresentada de maneira a ser uma disciplina distante das demais, a falta de correlação entre outras ciências é algo que merece e precisa ser revisto, não só nos cursos de formação de professores mas, como também no próprio currículo estabelecido nos cursos de licenciatura em Matemática, onde disciplinas como História da Matemática acabam ficando relegadas em relação as demais.

Se levarmos em consideração a abordagem de alguns autores, como Saviani (1980) e Libâneo (1989), onde afirmam que na pedagogia tradicional, o ator 
principal era o professor e o aluno se torna um mero espectador recebendo os conhecimentos de forma passiva, constatamos que hoje, no mundo atual, tal ação contemplativa se torna insuficiente. Os alunos podem e devem participar ativamente das aulas, discutindo, analisando e refletindo e o professor, quanto mais auxiliar o aluno nesse sentido, mais estará favorecendo para um crescimento, não só intelectual mas, um crescimento do ponto de vista social e cultural.

A prática do ensino de Matemática deve, portanto, ser algo que funcione nesse sentido e não apenas um ato mecânico de repasse de fórmulas e exercícios préprogramados. Matemática é ciência, e como tal não pode ser dissociada da realidade e tampouco trabalhada de forma vazia e sem contexto.

Segundo D’Ambrósio (1999, p.27), “Acredito que um dos maiores erros que se prática em educação, em particular na Educação Matemática, é desvincular a Matemática das outras atividades humanas.”

O desafio do ensino, não só da Matemática, mas geral é que, justamente falta ao professor habilidades/mecanismos para que, possa torná-los palatáveis conceitos e aplicações para um aluno que, imerso em um mundo cheio de distrações fáceis, está pouco preocupado em relacionar, por exemplo, assuntos matemáticos com os seus problemas do dia a dia.

\section{O uso da história}

Os problemas existem e são inúmeros e é por isso que acreditamos que o nosso trabalho pode auxiliar o professor no sentido de conseguir completar essa missão árdua de fazer com que a Matemática possa ser, se não seguida e amada pelos alunos mas, tratada com respeito e com entusiasmo pelos mesmos.

E é aí que surge uma questão, na verdade várias mas que, poderíamos sintetizar em três: quais são os meios para o professor fazer com que a Matemática seja algo realmente significante para a vida do aluno? Como ligar a teoria, por vezes 
abordada de maneira intricada e fria, a um exemplo vívido e útil para o aluno? Partindo de uma forma mais geral, o currículo, precisa ser melhor avaliado?

Tendo essa perspectiva, entendemos a História da Matemática como ferramenta capaz de resolver estes questionamentos. Podemos aplicar, através do uso da história, teoria e prática a demonstração de diversas fórmulas. Enfim, a aplicação deste tópico nas aulas de Matemática representa inúmeras formas para que o ensino se torne interessante, motivando os alunos para a construção de um conhecimento mais libertador e até, iniciando muitos destes na área da pesquisa e da construção do conhecimento através do estudo da padronização, investigação de problemas e suas correlações.

O fato é que ocorre frequentemente utilizar-se da História da Matemática como fato ilustrativo, presa a acontecimentos isolados, nomes de matemáticos famosos e datas. É preciso então, dar uma abordagem mais dinâmica ao ensino, favorecendo uma nova visão do objeto matemático em sala de aula.

De acordo com o PCN (Parâmetros Curriculares Nacionais):

Mostrar a Matemática como uma ciência desenvolvida pela humanidade ao longo do tempo auxilia na desmitificação dessa ciência, gerando atitudes e valores mais favoráveis do aluno frente aos saberes matemáticos.

O uso dos fatos históricos faz com que o aluno tenha uma real dimensão de cada conceito matemático, fazendo com que se situe sobre a geografia do local, da religião, dos costumes e da política. Afinal, conhecendo as contribuições de diferentes povos, podemos atribuir valor à própria cultura ao perceber-se inserido no contexto do aluno. Tudo isso, tendo como base a Matemática.

É importante salientar que, para os autores dos Parâmetros Curriculares Nacionais, a História da Matemática, se tratada de maneira específica, seria insuficiente para a contribuição do processo de ensino-aprendizagem. Nesse caso, 
portanto, é preciso observar o papel do professor para que possa fazer uma real articulação com os conteúdos ensinados para uma estratégia em sala de aula efetivamente eficaz.

Segundo Miguel e Miorim(2011), a abordagem dos conteúdos tem que servir ao aluno para atender os seguintes objetivos pedagógicos:

(I) a matemática como criação humana; (2) as razões pelas quais as pessoas fazem matemática; (3) as necessidades práticas, sociais, econômicas e físicas que servem de estimulo ao desenvolvimento das ideias matemáticas; (4) as conexões existentes entre matemática e filosofia, matemática e religião, etc.; (5) a curiosidade estritamente intelectual que pode levar à generalização e extensão de ideias e teorias; (6) as percepções que os próprios matemáticos tem do próprio objeto da matemática, as quais mudam e se desenvolvem com o tempo; (7) a natureza de uma estrutura, de uma axiomatização e de uma prova.

O professor pode mostrar, em sala que, como a Matemática sendo uma criação humana, cada tópico de seu conteúdo foi elaborado para atender a necessidade humana a medida que este foi evoluindo. Isso permite que o aluno veja que a construção da ciência pode ser algo interessante e instigante.

De acordo com D’Ámbrosio (1999)

"As ideias matemáticas comparecem em toda a evolução da humanidade, definindo estratégias de ação para lidar com o ambiente, criando e desenhando instrumentos para esse fim, e buscando explicações sobre os fatos e fenômenos da natureza e para própria existência. Em todos os momentos da história e em todas as civilizações, as ideias matemáticas estão presentes, em todas as formas de fazer e saber."

Nesse caso, portanto, a formação do professor se torna importante, contudo, o currículo que se estabelece nas licenciaturas é, por muitas vezes, mal estruturado, visando um ponto de vista apenas. O curso acaba sendo teórico demais, se distanciando da realidade existente na sala de aula.

[...] no I EPEM - Encontro Paulista de Educação Matemática, na atividade "Aspectos Históricos no processo de Ensino-aprendizagem da Matemática", foi destacado a "lamentável ausência da disciplina de 
História da Matemática, quer na quase totalidade dos currículos de licenciatura, quer na totalidade dos cursos de magistério" e que havia pequena oferta de cursos de História da Matemática para professores em exercício. Essa constatação aparece, também no Seminário Nacional de Matemática e nos IV e V Encontros Nacionais de Educação Matemática. (MIGUEL \& BRITO, apud. STAMATO, 2000;2)

Mesmo com a progressiva produção e pesquisa de conhecimentos relativos ao tema, a situação ainda se torna atual refletindo como uma deficiência nos cursos de formação inicial dos professores de Matemática.

Em relação aos Parâmetros Curriculares Nacionais (PCN), uma das orientações referentes à Matemática destacamos o seguinte trecho:

O ensino de História da Matemática permite recuperar sentido, e símbolo que foram ensinados tão arbitrários, seus traços, suas origens e a sua histórica permitem-nos restabelecer novos conceitos que a mesma visa. Neste sentido dois aspectos são fundamentais no ensino de Matemática: tais como: o primeiro refere-se à visão da Matemática que em geral norteia o ensino como pronta e acabada. O segundo é considerado como algo crucial, causando desgosto na maioria dos alunos pela Matemática o de que, compreendê-la se torna um privilégio das cabeças bem dotadas, o que acaba por negar todas as vivências anteriores relativas à qualificação já que não se enquadram na perfeição da Matemática.

Logo compreendemos que, quanto mais nos aproximarmos da realidade do aluno, menos desinteresse e apatia ele terá para novos conceitos e aplicações da Matemática.

Nos tempos atuais, devemos considerar que cada estudante exerce suas atividades num mundo informatizado, onde o fluxo de informações é extenso ao mesmo tempo que é fluido. E a escola, com suas disciplinas exibidas em estanque, dissociadas, distantes umas das outras, acaba por se tornar desinteressante e tediosa para muitos desses estudantes.

Segundo Gasperi, temos que:

“A organização da disciplina Matemática deve buscar a interdisciplinaridade e a contextualização para possibilitar ao aluno uma 
visão mais ampla sobre a matemática já que o ensino-aprendizagem deve permitir ao individuo dar conta de gerir sua vida pessoal e complexos desafios da vida contemporânea."

\section{História sendo o recurso didático}

Seguindo o uso da palavra metodologia, que nada mais é do que "percorrer um caminho", a abordagem histórica segue como sendo um destes caminhos pelo qual o professor pode escolher fazer para dar ênfase na construção dos conhecimentos matemáticos.

Segundo Brolezzi(1991), a História da Matemática pode representar três pontos positivos: temos uma ciência em fase de construção admitindo, dessa forma, uma lógica natural das coisas; o significado dos termos, expressões e fórmulas passa a ter um sentido muito mais amplo e verdadeiro para o aluno; o currículo se mostra ao aluno com muito mais universalidade, apresentando ao mesmo a capacidade de entender o estudo da evolução da matemática como um todo.

Ao iniciarmos determinado assunto, ao invés de apresentar as definições formais e fórmulas aparentemente sem sentido, o uso inicial de um problema ou episódio motivador constitui um caminho muito mais adequado na hora de introduzir novos conceitos.

Outro aspecto que podemos destacar quanto à presença da História da Matemática em sala de aula é quanto ao resgate que esse estudo proporciona das culturas menos favorecidas. Afinal de contas, não existe apenas uma só História da Matemática, uma estrutura única que segue em linha reta e indiferente, mas sim um conjunto amplo de saberes e práticas que vão muito além dos matemáticos europeus e que oferecem um importante papel sociocultural no rompimento de velhos paradigmas que persistem, por incrível que pareça, até hoje em nossa sociedade. 
Nesse sentido, Miguel e Miorim (201I), devem-se incorporar ao currículo as tradições matemáticas dos povos discriminados. Para isso, os autores utilizam-se de três estratégias para essa visão multifacetada:

I. Estratégia cultural

2. Estratégia social

3. Estratégia individual-coletiva

A primeira baseia-se exclusivamente em se ater aos aspectos de divulgação da história cultural de determinados povos. A segunda aborda aspectos relacionados à desmitificar certos preconceitos, modelos impostos e paradigmas sobre as capacidades matemáticas, por exemplo, de negros, mulheres ou índios. Por fim, o terceiro ataca os problemas realizados em sala de aula, tendo em vista a discussão de aspectos relacionados à matemática.

Um dos inúmeros exemplos que podem ser feitos é sobre o estudo da civilização maia, que foi dizimada pelos espanhóis no século XVI. De acordo com os registros históricos, os maias já, em sua sociedade, possuíam o símbolo para o número zero. O seu uso mais antigo é de uma inscrição do ano 36 a.C.. Seria irrelevante se, não fosse o fato de que a numeração criada pelos maias nunca recebeu nenhum tipo de influência da matemática que era criada na Europa ou em todo o Velho Mundo. Na Índia, o texto mais antigo sobre o número zero remonta do ano 458 d.C. Logo, um povo que era considerado "selvagem" ou primitivo utilizava-se de um símbolo para o zero cerca de 500 anos antes dele ter sido aceito pela sociedade considerada "evoluída" e "civilizada". Isso conseguimos apenas abordando o primeiro tópico, a da estratégia cultural.

Ao trabalharmos os preconceitos acerca das capacidades matemáticas dos povos menos favorecidos, seguindo a estratégia social, entendemos como a Matemática foi construída para ser aprendida por poucos “seres pensantes e 
abastados intelectualmente" que a visão europeia dominante impunha e deixamos claro que a ciência é algo com o qual todos podem ter acesso.

E, para finalizarmos, ao usar a estratégia coletiva-individual podemos recorrer a etnomatemática, explorando os problemas do dia a dia dos alunos e da sua comunidade. Para D’Ámbrosio(2012), “ a disciplina denominada Matemática é na verdade uma etonomatemática que se originou e se desenvolveu na Europa, que chegou a forma atual nos séculos XVI e XVII e então foi imposta a todo mundo no período colonial."

\section{Considerações finais}

Dessa forma, o uso da História da Matemática acaba que, nos fornecendo um contexto, uma motivação, uma causa e consequência sobre um assunto. Sendo assim, ao sabermos mais sobre a origem e evolução dos conhecimentos matemáticos entendemos o quanto esta ciência está interligada às demais atividades humanas.

\section{REFERÊNCIAS BIBLIOGRÁFICAS}

BRASIL. SECRETÁRIA DE EDUCAÇÃO FUNDAMENTAL. Parâmetros Curriculares Nacionais: matemática. Brasília. MEC/SEF; 1997.

BOYER, Carl. A História da Matemática. Ed. Da Universidade de São Paulo, 1974.

BROLEZZI, Antonio Carlos. A Arte de Contar. 1991. Dissertação de mestrado em educação - Universidade de São Paulo, São Paulo.

D’ÁMBROSIO, Ubiratan. Educação Matemática. 8 ed. Campinas; Papirus, 2012.

MIGUEL, Antonio; MIORIM, Maria Ângela. História da Matemática: propostas e desafios. 2. Ed. Belo Horizonte; Autêntica, 20Ir. 
MIGUEL, A.; MIORIN, M. A. A História na educação matemática: propostas e desafios. Belo Horizonte: Autêntica, 2004.

SAVIANI, D. Pedagogia histórico-crítica: primeiras aproximações. 2.ed.São Paulo: Cortez,1991. 